\section{PEP I News and Plans}

In March 1998 a meeting of PEP I was held in Mérida, Venezuela, which ended the first five years of coordinated activity along this transect. The meeting preceded the open science meeting of PAGES, which was held in London, UK the following month. As an outcome of these two meetings, at least seven areas of emphasis warrant continued coordination and analysis during the next phase of PEP I activity:

1. Human response to climate change: how have humans responded to climate change in the Americas during historical and prehistorical times?

2. Abrupt climate change: have there been abrupt changes in climate in the Americas during the late Pleistocene and Holocene, how geographically widespread were these events, and what is the phasing of these changes along the transect?

3. High-temporal resolution proxy records in the evaluation of climate change: how have the frequency of climate phenomena, such as the El Niño Southern Oscillation (ENSO), changed and how can discrete records of climate change be used in climate field reconstruction (CFR)?

4. Paleohydrology of the Americas: how have hydrologic resources changed through time, and what is the severity and recurrence of major droughts?

5. Variations in fire frequency as a linkage between climate change and ecosystem response: how can we better understand the relation between changes in fire frequency, climate change and ecosystem response on interannual to millennial temporal scales and local to subcontinental spatial scales?

6. Oceanic-atmospheric general circulation models and paleodata along the PEP I transect: how are paleoclimate data in the Americas integrated, made available, and how do they fit into data and modeling efforts such as BIOME 6000 and the Paleoclimate Modeling Intercomparison Project (PMIP)?
7. PEP Intercomparisons: how are variations in ENSO, monsoons, and the westerlies manifested along the different transects and what might this reveal about the mechanisms in propagating these climatic phenomena globally?

A subset of these topics will be chosen as themes for a series of smaller workshops. The workshops will be convened by leaders who will draw participants from throughout the Americas. The intent of the workshops will be to address the following questions:

1. What is the nature of the extant paleodata in the Americas and where are the critical gaps in these data, especially in the tropics and South America?

2. What is the current understanding of climatic teleconnections between the northern and southern hemispheres?

3. Other than a compendium of current projects and data, how can a synthesis of observations and interpretations be developed?

In addition to the workshops, we will convene special sessions at international meetings that will be of interest to the PEP I community and others. For example, in conjunction with the PAGES office, we convened a Union Session at the Fall 1999 Meeting of the American Geophysical Union in San Francisco titled, "Linking Continental and Ocean Paleorecords: The PEP Transects".

Keep an eye on the following web site for current activities along the PEP I transect (http://web.syr.edu/ goseltzel PEP1.html). Finally, feel free to contact the author with feedback and suggestions related to activities associated with the PEP I transect.

\section{Geoffrey O. Seltzer}

Department of Earth Sciences, Syracuse University, NY USA

goseltze@syr.edu

\section{Historical Solar Variability and Mid- Continent Drought}

The sun-climate connection has been controversial, mainly because of lack of physical mechanisms to explain climate response to small changes in solar irradiance during the 11-yr Schwabe sunspot cycle. Recently several empirical and modelling studies suggest that on multi-decadal to centennial timescales solar variability may be larger and may have more significant climate effects (Crowley \& Kim, 1996; Hansen et al., 1997; Fröhlich \& Lean, 1998). High-frequency forcings are dampened by the thermal inertia of the climate system, and sustained forcings tend to have more significant impact on climate. Many climate-forcing studies have focused on temperature responses at broader or even global scales (Mann et al., 1998), but there are few studies on changes in hydrological cycles (moisture regime), which are likely operating at a regional scale. Here we show that centennial dry-wet cycles in the northern Great Plains of North America correspond with all known historical solar variability. The results suggest a greater centennial solar variability, the existence of amplifying mechanisms in the interior of continent, or both.

A time series of salinity and drought proxy was developed from ostracodeshell Mg / Ca ratios at Rice Lake, North Dakota, USA $\left(48^{\circ} 00^{\prime} 29^{\prime \prime} \mathrm{N}, 101^{\circ} 31^{\prime} 49^{\prime \prime}\right.$ W), a topographically closed lake basin. The proxy data show significant centennial-scale wet-dry fluctuations (Fig. 1a), which demonstrate statistically significant periodicities of $\sim 400,200,130$ and 100 yr from spectral analysis (Yu \& Ito, 1999). These periods are similar to the principal solar oscillations (Stuiver \& Braziunas, 1989). This drought time series correlates remarkably well with residual $\Delta^{14} \mathrm{C}$ data from tree rings (Fig. 1b; Stuiver et al., 1998), a solar proxy (Stuiver \& Braziunas, 1989), and reconstructed solar irradiance for the past 400 years (Fig. 1c; Lean et al., 1995).

The dry periods at Rice Lake (green bands in Fig. 1a) correspond to solar minima and $\Delta^{14} \mathrm{C}$ maxima (green bands in Figs. 1b, and 1c), including the Maunder minimum when sunspots almost disappeared for 70 years in the $17^{\text {th }}$ cen- 